Portland State University

PDXScholar

\title{
21st Century Supply Chain Innovations in the Fast Food Industry
}

Saitoti Meekisho

Portland State University

Follow this and additional works at: https://pdxscholar.library.pdx.edu/honorstheses

Part of the Food and Beverage Management Commons, and the Operations and Supply Chain Management Commons

Let us know how access to this document benefits you.

\section{Recommended Citation}

Meekisho, Saitoti, "21st Century Supply Chain Innovations in the Fast Food Industry" (2020). University Honors Theses. Paper 858.

https://doi.org/10.15760/honors.879

This Thesis is brought to you for free and open access. It has been accepted for inclusion in University Honors Theses by an authorized administrator of PDXScholar. Please contact us if we can make this document more accessible: pdxscholar@pdx.edu. 
$21^{\text {st }}$ Century Supply Chain Innovations in the Fast Food Industry

by

Saitoti Meekisho

An undergraduate honors thesis submitted in partial fulfillment of the

requirements for the degree of

Bachelor of Science

in

University Honors

and

Business Administration

Thesis Adviser

Scott DuHadway

Portland State University

2020 


\begin{abstract}
In the last 20 years, attending to consumer demand for at-home delivery has been an area of concern for supply chain specialists in the restaurant industry. Applying logistically-sound processes for food delivery to its final destination (Also called last-mile delivery) has become a necessity for restaurants to gain and sustain competitive advantages. This research seeks to catalog the dynamic last-mile delivery innovations by restaurants per consumer demand, assess the competitive sustainability of four current food delivery methods (takeout, restaurant delivery, $3^{\text {rd }}$ party company delivery, \& monthly meal delivery) using the VRIN framework, and suggest collaborative delivery strategies for future researchers and restaurateurs to consider.
\end{abstract}

Keywords: last-mile delivery; supply chain; OFD; collaboration; sustainability; delivery; VRIN

\title{
Background
}

Last-mile delivery broadly defines the delivery of finished goods to their final destination. This final destination could be a retail store, office building, an apartment, or other such locations. The complexity of last-mile delivery components is highly-variable depending on the structure of a company's industry, the competitive capabilities, and consumer expectations. In the last twenty years, fast food restaurants' supply chains have been pivoting \& scaling to data-driven delivery strategies to further current core competencies and react to the dynamically changing competitive landscape in the industry. (Fancello et al, 2017).

Big data is collected through online food delivery (OFD) services. The creation and analytics of these OFD's have been the preeminent industry innovation in $21^{\text {st }}$ century. OFD's allow restaurants to interact with more potential customers, and provide them place utility 
(Making goods and services easily accessible). As consumers become more tech savvy, it is critical that restaurants offer sound OFD interfaces for customers to have consistent, high-quality interactions with the restaurants they choose to support (Suhartanto, 2019).

Creating an OFD doesn't guarantee a restaurant's competitive viability in the everchanging industry. While these services can identify market potentials, top-selling items, and other such characteristics, restaurants become competitive when they use this data to make decisions. The resources and strategies for physically delivering meals to their final destination will differ dependent on a restaurant's last-mile delivery strategy. While there is a plethora of highly variable last-mile delivery strategies present in today's fast food industry, this literature review will critically review four basic, highly-visible strategies, and compare the competitive viability of each.

\section{Research Question}

How do last-mile delivery strategies help restaurants compete in a delivery-driven market?

\section{VRIN Framework}

This question will be approached using the VRIN framework. VRIN is a qualitative competitive advantage scale that measures value, rareness, imitability, and organization of delivery strategies within supply chains. Value measures a customer's willingness to pay and ability to save money. Rareness tracks the visibility of the strategy in the industry. Imitable qualifies the replicability of the strategy by a new industry competitor. Non-substitutable clarifies the presence of alternative methods (Internal or external to the industry) that provide similar customer value with another delivery method. For a strategy to be considered sustainable long-term, each of the four categories must be fulfilled. This analysis will show the relative 
strengths and weaknesses of delivery strategies and the need for innovative delivery strategies to emerge.

\section{Overview of Four Delivery Strategies}

Four delivery methods will be analyzed through the VRIN framework. The first method is takeout. It is a dated and highly common method that gives customers the convenience of ordering food before-hand and taking their order home. The second method will be restaurant delivery, another common method that has been used for several years. Restaurants hire their own delivery drivers to deliver food from the restaurant directly to consumer's desired destination. The third method is $3^{\text {rd }}$ party delivery. The delivery market has become saturated with these $3^{\text {rd }}$ party services in the last few years with apps like GrubHub, DoorDash, UberEats, and many more. The fourth method will be monthly meal delivery. In this method, customers curate a month worth of meals delivered to them. These meals require little-to-no prep, simply microwaving or pan frying the meal to bring it to room temp. The fifth method is collaborative kitchens, which are not currently present in the market. Further information on this method will be shared in succeeding paragraphs.

\section{Delivery Method 1: Takeout}

The first method is takeout. In this method, customers place orders and take the food away to eat at home. This method is valuable because it gives customers the convenience to preorder meals, bypass ordering lines, and eat at a preferred destination (Home, office, etc). It is not rare, since it is a very dated method that is very visible in the industry. Additionally, it is not inimitable; it is a simple model for new-coming competitors to replicate. Lastly, it is not non- 
substitutable since there are various delivery methods that assist customers in bypassing lines and eating meals at preferred locations (To be discussed in succeeding paragraphs).

\section{Delivery Method 2: Restaurant Delivery}

The second method is restaurant delivery. This method involves restaurants creating delivery driver positions (Internal to the company) and delivering orders directly to customers. This method is valuable since it offers customers at-home delivery for a manageable fee. Dominos created additional customer value with their patented Dominos Pizza Tracker. Released in 2008 , the tracker gave customers real-time updates order creation and delivery process (Figure 1). This provided an elevated level of visibility between fast food restaurants and customers; value innovation un-seen in the industry (Taylor, 2014).

It is not rare since it is a common delivery method offered by countless restaurants. Additionally, restaurant delivery is not inimitable; companies can easily replicate the service and deliver orders to their customers. This method is also not non-substitutable since there are other ways for consumers to get their meals delivered to their homes.

\section{Delivery Method 3: $3^{\text {rd }}$ Party Delivery}

$3^{\text {rd }}$ party delivery is a newer, highly-visible delivery strategy in the market. In this delivery method, companies (Such as GrubHub, UberEats, DoorDash, etc) have created OFD's for customers to order from their favorite restaurants. These companies offer minimal service and delivery fees for drivers to pick up order, and deliver straight to customer's homes. Companies like GrubHub have adopted order tracking models similar to Domino's pizza tracker (Figure 2). 
The continued transparency between businesses and customer for order status makes this food delivery method valuable. Though, it is not rare since the OFD model is highly replicable and visible in the industry. It is imitable since it has been re-created by various companies. Lastly, it not non-substitutable, since customers have different ways to get their food orders delivered.

\section{Delivery Method 4: Monthly Meal Delivery}

The fourth method is monthly meal delivery. This method offers tremendous customer value by offering prepped meals for on-the go lifestyles. Additionally, companies like Freshly offer meal selections, allowing customers to coordinate their ideal meals for the entire month (Figure 4). This method is not rare since a similar delivery method is present in the market. Additionally, this method is imitable, allowing new industry members to adopt a similar model. Lastly it is not non-substitutable since consumers are still capable of acquiring a month's worth of food in other ways (Ex] Grocery shopping).

\section{Innovation Required for Competitive Advantage}

The four food delivery methods listed thus far have created unique ways to offer customer value. Key methods include order tracking software, prepped meal selection, and small fees for at-home delivery. Though, none of the four methods are rare, non-imitable, nor are they non-substitutable. According to the VRIN framework, a strategy that does not incorporate all four criterion offers only a temporary competitive advantage. The critical interest of this literature review is to highlight short-term success these methods offer, and consider last-mile delivery strategies to incorporate a sustainable delivery strategy for fast food restaurants.

\section{New Delivery Method: Collaborative Kitchens}


The original method that incorporates the new innovation required for the industry is collaborative kitchens. These kitchens will be large facilities that can host up to 10 restaurants individual cooking stations. To minimize the delivery time for delivery drivers, these facilities will be constructed in significant locations where restaurants have high sales from their OFD's. Locating the ideal facility locations calls upon a dated, yet effective supply chain theory, the square root law.

This law states that using geographic coordinates of sales totals can be used to find ideal locations for warehouses (Oeser \& Romano, 2016). Though the literature on the square root law is significantly older compared to the rest of the research produced by this study's discourse community, it is a viable means for restaurants to explore prime locations to place new restaurants. Strategically locating the collaborative kitchen will restaurants to operate in highservice areas, and reduce costs for their delivery drivers.

Similar to the square root law, supply chain managers within the fast food industry can consider using geographic postponement. This strategy helps identify strategic locations for warehouses (Pagh \& Cooper, 1998). Locating warehouses near a group of restaurants will allow for quicker replenishment of products.

This method provides incredible value for customers and restaurants. Customers can count on shorter delivery time windows, and reduced service costs. Restaurants can appreciate being closer to high-service areas, getting expedited supply replenishment, and sharing overhead costs (Of the shared facility) with other restaurants. Collaborative kitchens are also rare since the method is not currently visible in the industry. It is non-imitable because the city planning, and collaboration amongst restaurants is tedious, prolonged process that can't be easily re-created by 
new competitors. Lastly, the method non-substitutable, since the collaborative kitchens unique service can't be replaced by another delivery method.

\section{Conclusion}

While the VRIN framework clearly highlights the temporary nature of current delivery methodologies, it is limited in its ability to measure when the methods will stop offering competitive advantages, and how to create new methods. Though the collaborative kitchen method suffices all four categories of the VRIN, (Figure 5) it is highly-idealistic method attempting to create collaboration amongst competing restaurants, optimize costs, and increase customer value. The idea calls upon city planning, last-mile delivery, and construction disciplines to further the research necessary to actualize the presence of collaborative kitchens in the marketplace.

Collaborative kitchens are not the sole innovative method that offers a sustained competitive advantage in the industry. Rather a conversation starter about the need for proactive innovation to address customers' demand, and provide the maximum value with a competitivelyviable last-mile delivery strategy. 


\section{Appendix A: Interviews}

\section{Interview I}

Date of Interview: Monday, February 17, 2020

Interviewee: Whitney Jagielski

Business Name: The BackBurner LLC

1) How long has your business been operating?

- First week of July

- Person-to-person advertising. Facebook (Paid) promos

2) What cuisine does your business offer?

- Summer- Sandwiches \& Burgers

- (First week of March) Spring- Pierogis \& Wings

3) What is the average cost of a customer transaction?

- $\$ 12$ per person

4) Have you noticed any competitors using an offering a similar cuisine? Similar pricing strategy?

- Not noticed similar cuisine

- Another pierogi shop in Hawthorne

- Unsure of prices

5) Do you use food delivery apps (For personal use)?

- Yes

- UberEats primarily

- Caviar

- GrubHub

6) Does your business have delivery options? If so, what kind?

- GrubHub, UberEats, Post Mates.

- Free promo for 30 days (on each app) 
- Reached out to each app

- Filled out a general application

- Phone meeting to discuss menu

- GrubHub hired a one-hour photographer

- Plans to continue using 3 apps

$>$ Anticipates more foot traffic, less need for apps

$>$ Sees the apps as promotion, not profit-seeking

7) What are some substitutes for delivery options?

- Food Prep

- Common practice for pierogi

8) Do you view food delivery apps as threats or opportunities for your business?

- Opportunity for promotion

- Does not view them as threats

9) Do you see your business partnering with food delivery apps?

- Yes

10) What successful business and/or delivery strategies have you noticed from your competitors?

- Southern Kitchen (BBQ Truck), heavily involved in local church

- Church-goers would call in ahead

○ BIG orders

11) What do you think your business is not currently offering that it can?

- More hours of availability.

- Only open during lunch hours.

- Hire a part-time employee

- Requires HR focus

12) What do you think is the future of food delivery methods for the fast food industry?

- Scooter Apps \& Food Delivery Apps

○ Joint venture

- Designate scooters for certain delivery apps.

13) How would you feel about a collaborative kitchen with other companies? 
- Interested

- Walk-in hours \& delivery-only hours

- The Commissary Kitchen (SE Portland on McLoughlin) has food windows.

- Defined delivery spaces

○ Similar to Jimmy John's small delivery window 
Date of Interview: Wednesday, February 19, 2020

Interviewee: Fouad Ismail

Business Name: Front Porch LLC

1) How long has your business been operating?

- 6 months

- August 2019

2) What cuisine does your business offer?

- Southern Cooking Fried Chicken

- Collard Greens

- Baby Back Ribs

3) What is the average cost of a customer transaction?

- $\$ 9-16$

- Sandwich \& Fries

- Entrée plate. Main entrée, 1-2 sides, \& a drink

4) Have you noticed any competitors using an offering a similar cuisine? Similar pricing strategy?

- BBQ food cart in the food cart community, "Wood-Smoke."

- Big's Chicken down the road.

5) Do you use food delivery apps (For personal use)?

- Post Mates

- GrubHub

6) Does your business have delivery options? If so, what kind?

- Not currently

- Notes he's heard they take large percentages

7) What are some substitutes for delivery options?

- Looking into catering opportunities 
- Mayor's events

- Office deliveries

- Social Media

- Nike Orders

8) Do you view food delivery apps as threats or opportunities for your business?

- Opportunity

- Prefers foot traffic

- Feels foot traffic improves marketing

- Apps provide more marketing profit

- Extra money gives convenience

9) Do you see your business partnering with food delivery apps?

- In the future

○ Depends on fees and marketing opportunities

- GrubHub

- Post Mates

- DoorDash

10) What successful business and/or delivery strategies have you noticed from your competitors?

- Offering discounts

If reviews are provided

$>$ Views Yelp as an extreme helpful tool

○ Helps customers feel they won

- Punch Cards

11) What do you think your business is not currently offering that it can?

- A larger, more standardized menu

- Sound food prep strategies. Cook-to-order

- Providing more menu options that are cook-to-order

12) What do you think is the future of food delivery methods for the fast food industry?

- Feels food delivery apps are still new and will prosper 
13) How would you feel about a collaborative kitchen with other companies?

- Brings in larger clientele

- Cheaper overhead costs

- Creates community for customers \& businesses

\section{Additional Information}

1) Property Acquisition

- Found opportunity in expanding territory

- Didn't want to invest in Brick \& Mortar

- Very clean well-managed food cart pod

- Entered waiting list on property website

- By-passed list due to differentiation

- Licensing \& Fees w/ personal lawyer 


\section{Appendix B: OFD Examples}

Figure 1: Domino's Pizza Tracker

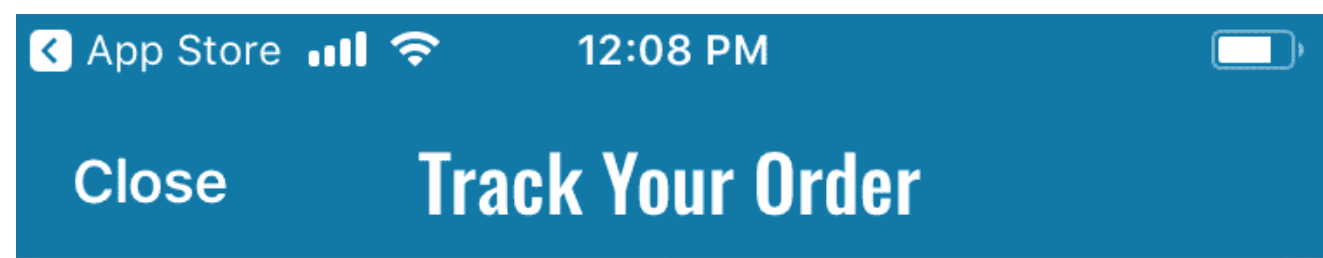

\section{DOMINO'S TRACKER}

Know the status of your order, from the moment it's placed to the second it leaves our store for delivery or is ready to be picked up.

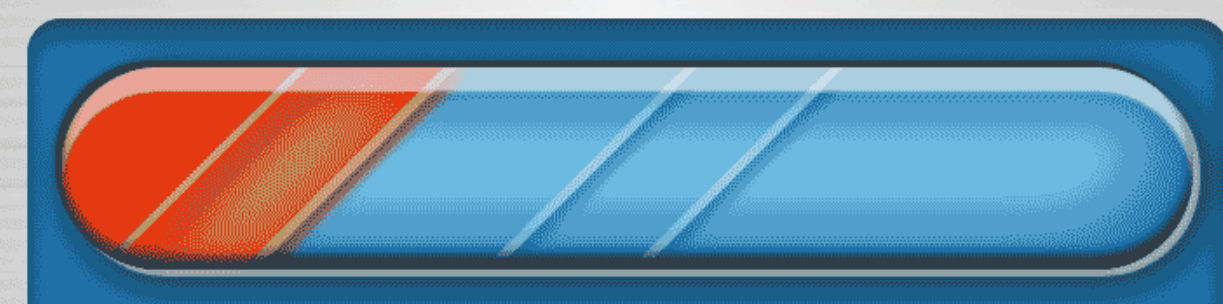

WE'RE FIRING IT UP! - SEBASTIAN began custom making your order at 12:06 PM

(Bindley, 2017) 
Figure 2: DoorDash Order Status

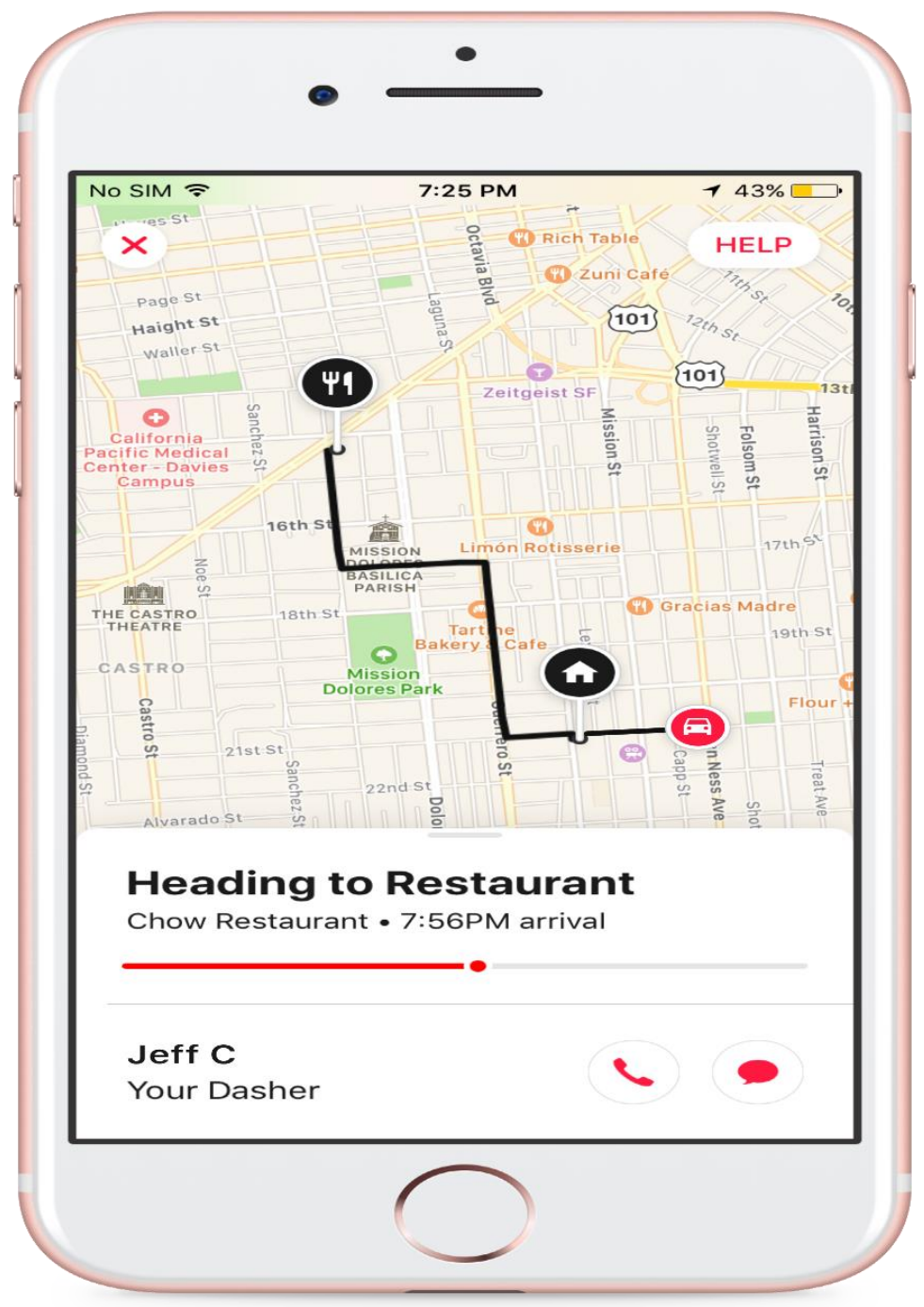

(Liu, 2017) 
Figure 3: Freshly Meal Selection

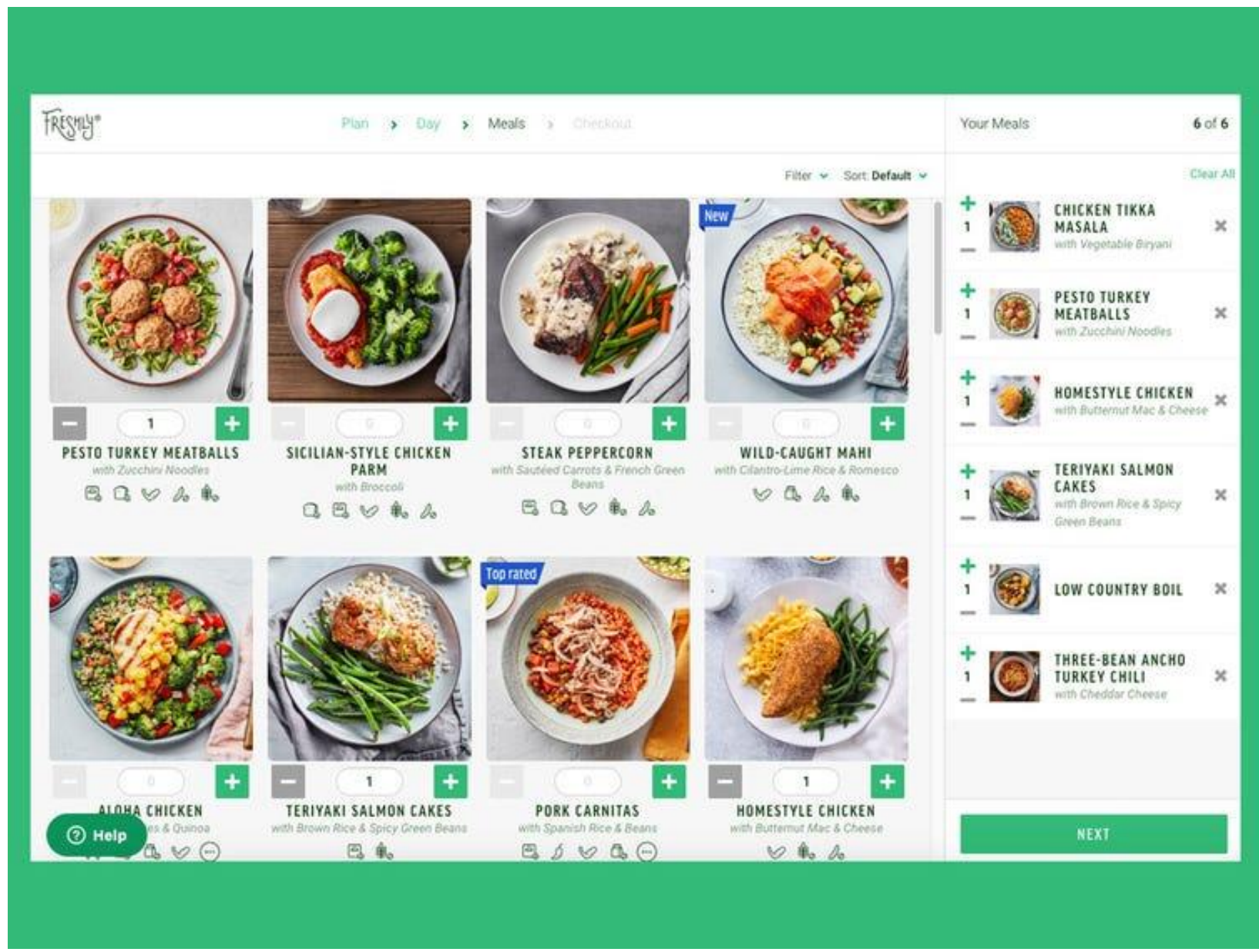

(Rosmarin, 2020) 


\section{Appendix C: VRIN Method Checklist}

Figure 5: Delivery Method Checklist

\begin{tabular}{|c|c|c|c|c|c|}
\hline $\begin{array}{l}\text { Delivery } \\
\text { Method }\end{array}$ & Valuable? & Rare? & $\begin{array}{l}\text { Non- } \\
\text { Imitable? }\end{array}$ & $\begin{array}{l}\text { Non- } \\
\text { Substitutable? }\end{array}$ & $\begin{array}{l}\text { Sustainable } \\
\text { Advantage? }\end{array}$ \\
\hline Takeout & Yes & No & No & No & No \\
\hline $\begin{array}{l}\text { Restaurant } \\
\text { Delivery }\end{array}$ & Yes & No & No & No & No \\
\hline $\begin{array}{l}3^{\text {rd }} \text { Party } \\
\text { Delivery }\end{array}$ & Yes & No & No & No & No \\
\hline $\begin{array}{l}\text { Monthly } \\
\text { Meal } \\
\text { Delivery }\end{array}$ & Yes & No & No & No & No \\
\hline $\begin{array}{l}\text { Collaborative } \\
\text { Kitchens }\end{array}$ & Yes & Yes & Yes & Yes & Yes \\
\hline
\end{tabular}




\section{Bibliography}

Barney, J. (1991). Firm Resources and Sustained Competitive Advantage. Journal of Management, 17(1), 99-120.

Bindley, K. (2017). “Domino’s tracking app tells you who made your pizza- or does it?” The Wall Street Journal.

Boyer, K., Prud'homme, A. \& Chung, W. (2009). The last mile challenge: evaluating effects of customer density and delivery window patterns. Journal of Business Logistics, 30, (1), $185-201$.

Fancello, G., Paddeu, D., \& Fadda, P. (2017). Investigating last food mile deliveries: A case study approach to identify needs of food delivery demand. Research in Transportation Economics, 65, (1), 56-66.

Giret, A., Carrascosa, C., Julian, V., Rebollo, M. \& Botti, V. (2018). A crowdsourcing approach for sustainable last mile delivery. Sustainability, 10, (12), 45-63.

Liu, J. (2017). "New features to better find, track, and rate your deliveries". DoorDash Blog.

Oeser, G., \& Romano, P. (2016). An empirical examination of the assumptions of the Square Root Law for inventory centralisation and decentralisation. International Journal of Production Research, 54, (8), 2298-2319.

Pagh, J. \& Cooper, M. (1998). "Supply chain postponement and speculation strategies: how to choose the right strategy.

Rosmarin, R. (2020). "I tried a ready-made meal delivery service that makes it easy to eat healthy on busy days.” Business Insider 
Seung Yoon Ko, Sung Won Cho, \& Chulung Lee. (2018). Pricing and Collaboration in Last Mile Delivery Services. Sustainability, 10, (12), 45-60.

Stank, T., Crum, M. \& Arango, M. (1999). Benefits of interfirm coordination in food industry supply chains. Journal of Business Logistics, 20, (2), 21-41.

Suhartanto, D., Ali, M., Tan, K., Sjahroeddin, F., \& Kusdibyo, L. (2019). “Loyalty toward online food delivery service: the role of e-service quality and food quality." Journal of Foodservice Business Research, 22, (1), 81-97.

Taylor, D. (2014). "Real-time service encounters and customer satisfaction: online monitoring of core service delivery". Academy of Marketing Science. 44-48.

Yeo, V., Goh, See-Kwong., \& Rezaei, S. (2017). "Consumer experiences, attitude and behavioral intention toward online food delivery (OFD) services." Journal of Retailing and Consumer Services, 35, (4),150-162. 